\title{
Clinical signs predictive of severe illness in young Pakistani infants
}

\author{
Shahira Shahid ${ }^{1}$, Shiyam Sunder Tikmani ${ }^{2}$, Kanwal Nayani ${ }^{1}$, Ayesha Munir ${ }^{1}$, Nick Brown ${ }^{3}$, Anita K. M. Zaidi ${ }^{1}$, \\ Fyezah Jehan ${ }^{1}$ and Muhammad Imran Nisar ${ }^{1 *}$ (1)
}

\begin{abstract}
Objective: Early detection of specific signs and symptoms to predict severe illness is essential to prevent infant mortality. As a continuation of the results from the multicenter Young Infants Clinical Signs and Symptoms (YICSS) study, we present here the performance of the seven-sign algorithm in 3 age categories (0-6 days, 7-27 days and 28-59 days) in Pakistani infants aged 0-59 days.

Results: From September 2003 to November 2004, 2950 infants were enrolled (age group 0-6 days=1633, $7-27$ days $=817,28-59$ days $=500)$. The common reason for seeking care was umbilical redness or discharge $(29.2 \%)$ in the 0-6 days group. Older age groups presented with cough (16.9\%) in the 7-27 age group and (26.9\%) infants in the 28-59 days group. Severe infection/sepsis was the most common primary diagnoses in infants requiring hospitalization across all age groups. The algorithm performed well in every age group, with a sensitivity of $85.9 \%$ and specificity of $71.6 \%$ in the $0-6$ days age group and a sensitivity of $80.5 \%$ and specificity of $80.2 \%$ in the $28-59$ days group; the sensitivity was slightly lower in the 7-27 age group (72.4\%) but the specificity remained high (83.1\%).
\end{abstract}

Keywords: Young infants, Clinical signs, Severe illness requiring hospitalization, Pakistan, Community

\section{Introduction}

Neonatal period accounted for approximately $45 \%$ of all under-five mortality in 2015 particularly in developing countries $[1,2]$. A multi-country study called the Young Infant Clinical Signs Study (YICSS) was undertaken in developing countries (Dhaka, Bangladesh; La Paz, Bolivia; Kumasi, Ghana; Chandigarh, India; Delhi, India; Durban, South Africa and Karachi, Pakistan). It assessed predictive values of several symptoms and signs as elicited by a primary health worker in determining severe illness requiring hospitalization by using a unified protocol [3]. The study analyzed data from 3177 infants aged 0-6 days and 5712 infants aged 7-59 days and an initial set of 12 symptoms reduced to 7 key indicators of disease

\footnotetext{
${ }^{*}$ Correspondence: imran.nisar@aku.edu

${ }^{1}$ Department of Pediatrics and Child Health, Aga Khan University, Karachi, Pakistan

Full list of author information is available at the end of the article
}

severity. The most important signs and symptoms were noted to be: history of difficulty feeding; convulsions; movement only when stimulated; respiratory rate of 60 breaths per minute or more; severe chest indrawing and temperature of $37.5^{\circ} \mathrm{C}$ or more or below $35.5{ }^{\circ} \mathrm{C}$ [3-7]. These results were used to update the Integrated Management of Childhood Illness (IMCI) guidelines [8].

This paper reports experience from the contributory study undertaken by the Aga Khan University in Karachi, Pakistan, where, unlike all other sites, only data from the community was used. We report the data from 1633 infants aged 0-6 days, 817 infants aged 7-27 days and 500 infants aged 28-59 days, the largest contribution to the YICSS by a single country, with the sample size for neonates less than a week old in our study being more than half of the total sample size of neonates aged $0-6$ days in the main study. The objective of this study is to validate the clinical signs and symptoms observed

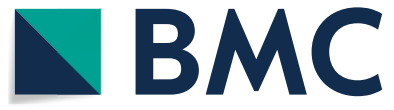

(c) The Author(s) 2021. This article is licensed under a Creative Commons Attribution 4.0 International License, which permits use, sharing, adaptation, distribution and reproduction in any medium or format, as long as you give appropriate credit to the original author(s) and the source, provide a link to the Creative Commons licence, and indicate if changes were made. The images or other third party material in this article are included in the article's Creative Commons licence, unless indicated otherwise in a credit line to the material. If material is not included in the article's Creative Commons licence and your intended use is not permitted by statutory regulation or exceeds the permitted use, you will need to obtain permission directly from the copyright holder. To view a copy of this licence, visit http://creativeco mmons.org/licenses/by/4.0/. The Creative Commons Public Domain Dedication waiver (http://creativecommons.org/publicdomain/ zero/1.0/) applies to the data made available in this article, unless otherwise stated in a credit line to the data. 
in infants to identify severe illness and predict hospital admissions.

\section{Main text Methods}

The study was undertaken in three field sites in Karachi, Pakistan: Bilal Colony, Rehri Goth and Ibrahim Hyderi from 10th September 2003 to 13th November 2004. Two of these are peri-urban sites with Primary Healthcare Centers (PHC) run by the Aga Khan University Hospital (AKUH), and a third (Bilal Colony) is a densely populated urban squatter settlement. A uniform methodology was used at all study sites, details of which are described in the main YICSS paper [3]. All infants under the age of 60 days who were either self-referred to our center or referred by Community Health Workers (CHW) during community surveillance were enrolled after written informed consent was taken from the parent/guardian. Enrollment took place 4 days a week, i.e. Monday, Tuesday, Thursday, and Friday from 9 am to 3 pm each day. Infants who lived outside the catchment area, sick infants with a history of hospitalization in the previous 2 weeks, along with those who had a lethal malformation or those requiring emergent treatment, and those whose parents or guardians did not consent were excluded.

\section{Study procedure}

Young infants were first screened by a trained LHV (Lady Health Visitor) (Study Person A) after determining eligibility and taking informed consent. Socio-demographic details and clinical signs were recorded from a prespecified list on form $A$. The infant was then referred to an experienced pediatrician (Study person B) who was blinded to the assessment of the LHV. The pediatrician determined the need for immediate referral of the infants to a tertiary care hospital, the National Institute of Child Health $(\mathrm{NICH})$, based on their clinical presentation. Infant pulse and oximetry were also performed. Training sessions for the LHVs and pediatricians were conducted in which clinical signs were demonstrated using videos. All infants who were not referred for admission were followed-up within $48 \mathrm{~h}$ during which they were reevaluated for any improvement or deterioration. In case a follow-up visit was not made, attempts were made to contact the child's parent or guardian using telephone otherwise a home visit was made. A review committee of three pediatricians reviewed records of $20 \%$ of all admitted infants and $10 \%$ of all infants who were not admitted. The feedback was provided to Study Person B.

\section{Data entry, cleaning, and management}

All forms were checked for completion and correctness and then entered into an Epi-Data database (V.2.1,
Epidata Association, Odense Denmark). Data files were double checked by the international data coordination center in Melbourne, Australia, for consistency and quality.

\section{Statistical methods}

Using the methods described in the main paper, we replicated the analysis for 0-6-day age group in Pakistani infants. Our primary outcome was the classification of severe illness requiring hospitalization by Study Person B. Univariate analysis of the association between the primary outcome and individual clinical signs and symptoms was conducted and Odds Ratio (OR) with 95\% Confidence Intervals (CI) were calculated. Since decision to refer infants with jaundice is based on the level of hyperbilirubinemia and not just signs and symptoms alone, these children were included in the non-severe illness category [3]. We calculated sensitivity and specificity of individual signs in the WHO seven sign algorithm [8]. The algorithm derived from the $0-6$ days group was then used to calculate sensitivity and specificity for 7-27and 28-59-days age group. All analysis was done using Stata version 12.0.

\section{Ethical clearance}

The study was approved by the Ethics Committee at Aga Khan University Hospital and the WHO Ethical Research Committee.

\section{Results}

A total of 3011 infants were triaged, out of which 2950 were enrolled. Of all the three age groups, 329 infants required hospitalization, and 92 were admitted. The flow of infants in the study is given in Additional file 1: Figure S1.

Table 1 shows the baseline characteristics of the enrolled infants, $55 \%$ of the infants were aged 0-6 days, $28 \%$ were aged $7-27$ days and $17 \%$ were aged $28-59$ days. Majority of the infants were delivered at home (78\%). The most common reason for seeking care in the $0-6$ days group was umbilical redness or discharge (29.2\%), followed by excessive crying (11.1\%). In the older age group, $16.9 \%$ infants in the 7-27 age group presented with cough, $14.1 \%$ presented with fever and $9.7 \%$ presented with diarrhea. The most common primary diagnosis (assessed by the pediatrician) in the 0-6 days group was localised infection (including skin, eye, oral and umbilical infections) $44.7 \%$. In the older age group, the most common primary diagnosis was found to be upper respiratory tract infection (URTI), with $33.6 \%$ diagnosed infants in the 7-27 days group and $32.6 \%$ in the $28-59$ days group (Table 2). 
Table 1 Baseline clinical characteristics of study groups

\begin{tabular}{|c|c|c|}
\hline \multirow{2}{*}{$\begin{array}{l}\text { Characteristics } \\
0-6 \text { days }\end{array}$} & \multicolumn{2}{|c|}{$\begin{array}{l}\text { Number of infants } \\
N=2950\end{array}$} \\
\hline & 1633 & $(55 \%)$ \\
\hline $7-27$ days & 817 & $(28 \%)$ \\
\hline 28-59 days & 500 & $(17 \%)$ \\
\hline Male & 1467 & $(50 \%)$ \\
\hline Exclusive breastfeeding & 1578 & $(54 \%)$ \\
\hline \multicolumn{3}{|l|}{ Vital signs } \\
\hline Pulse (> 160 bpm) & 30 & $(1 \%)$ \\
\hline Pulse oximetry (<95\%) & 513 & $(17 \%)$ \\
\hline \multicolumn{3}{|l|}{ Obstetric history } \\
\hline Home delivery & 2298 & $(78 \%)$ \\
\hline Delivered by skilled attendant & 720 & $(24 \%)$ \\
\hline Low Birth Weight (<2500 g) & 942 & $(32 \%)$ \\
\hline Parity $>0$ & 520 & $(18 \%)$ \\
\hline Gestational age (<37 weeks) & 59 & $(2 \%)$ \\
\hline Maternal tetanus toxoid & 645 & $(22 \%)$ \\
\hline Antenatal care (3 visits or more) & 624 & $(21 \%)$ \\
\hline Diabetes during pregnancy & 5 & $(0 \%)$ \\
\hline Anemia during pregnancy & 1049 & $(36 \%)$ \\
\hline UTI during pregnancy & 35 & $(1 \%)$ \\
\hline Fever at the time of delivery & 382 & $(13 \%)$ \\
\hline Prolonged labor & 191 & $(7 \%)$ \\
\hline Prolonged rupture of membranes & 170 & $(6 \%)$ \\
\hline Vaginal delivery & 2878 & (98\%) \\
\hline
\end{tabular}

Data are in $\mathrm{n}(\%)$ or mean (SD)

Additional file 1: Table S1 describes the individual signs and symptoms in predicting the need for hospitalization in each age group. History of fever, history of no cry at birth, respiratory rate $>60$ breaths per minute and redness and pus around the umbilicus emerged as the most prevalent signs in the 0-6 days group. In the older groups, history of fever remained the most prevalent sign. We compared the point estimates of odds ratios for different signs and symptoms. Among the most common signs (prevalence more than 10\%), signs such as moving only on stimulation, lethargy, severe chest indrawing, and nasal flaring appeared as having the greatest odds of predicting severe illness requiring hospitalization in the 0-6 days group, while in the older age groups, movement only on stimulation and prolonged capillary refill had higher odds as compared to other signs and symptoms in the group.

We used the WHO algorithm for young infants for evaluating the effectiveness of signs in the Pakistani population [8]. As reported in the main paper, we reported an identical sensitivity of $85.9 \%$ and specificity of $71.6 \%$ in the 0-6-day age group. The same model was applied to the older age groups. In the 7-27 days age group, the algorithm had a sensitivity of $72.4 \%$ and a specificity of $83.1 \%$ while in the $28-59$ days group, it had a sensitivity of $80.5 \%$ and a specificity of $80.2 \%$. Sensitivity and specificity of each sign in predicting the need for hospitalization in young Pakistani infants is given in Table 3.

\section{Discussion}

Our results show that the WHO IMCI algorithm for predicting severe illness is effective in young Pakistani infants aged 0-59 days. The 7-sign algorithm (history of difficult feeding, movement only when stimulated, temperature $<35.5$, temperature $\geq 37.5$, respiratory rate $>60$, severe chest indrawing and history of convulsions) derived from infants aged 0-6 days is predictive of severe illness not only in that age group, but is also applicable to older infants aged 7-27 and 28-59 days. This study was conducted as part of a multicenter trial to assess the signs and symptoms of severe illness in Karachi, Pakistan. The study sites were low-income urban and peri-urban areas with limited access to primary healthcare facilities.

The most common primary diagnosis in infants requiring hospitalization was severe infections/sepsis, with a prevalence of $44 \%$ in the $0-6$ days group, $74 \%$ in the 7-27 days group and $61 \%$ in the $28-59$ days group therefore early detection of warning signs by health workers in neonates and infants is crucial [9]. The IMCI criteria includes seven signs and the presence of any clinical sign is considered to be suspicious for a serious bacterial illness [8]. This is especially important for infants aged 0-6 days, since most of the neonatal deaths take place in the first week of life [2]. The signs usually included in the algorithm if used alone have a limited prediction value for referral because they are mostly accompanied by other common signs and symptoms. As a result, they are difficult to retain and teach because they are infrequently seen alone $[6,10]$. In our univariate analysis, we focused on signs and symptoms with a minimum of $5 \%$ prevalence. Having an acceptable level of sensitivity and specificity, and consisting of only seven signs, the algorithm proves to be a simpler criterion of recognizing severe illness in neonates. It is quick and easy to teach and retain as far as the health workers in the community settings are concerned.

An important strength of our study was that it included a relatively higher number of infants aged less than 7 days which helped in generating signs and symptoms for this age category with a greater accuracy and precision as compared to other similar studies in different countries that had a lower number [3]. Moreover, our study was conducted in a community level setting with no health insurance or tertiary care coverage as compared to the same study in other centers [3]. Our results show that the seven-sign algorithm is indeed effective in predicting the 


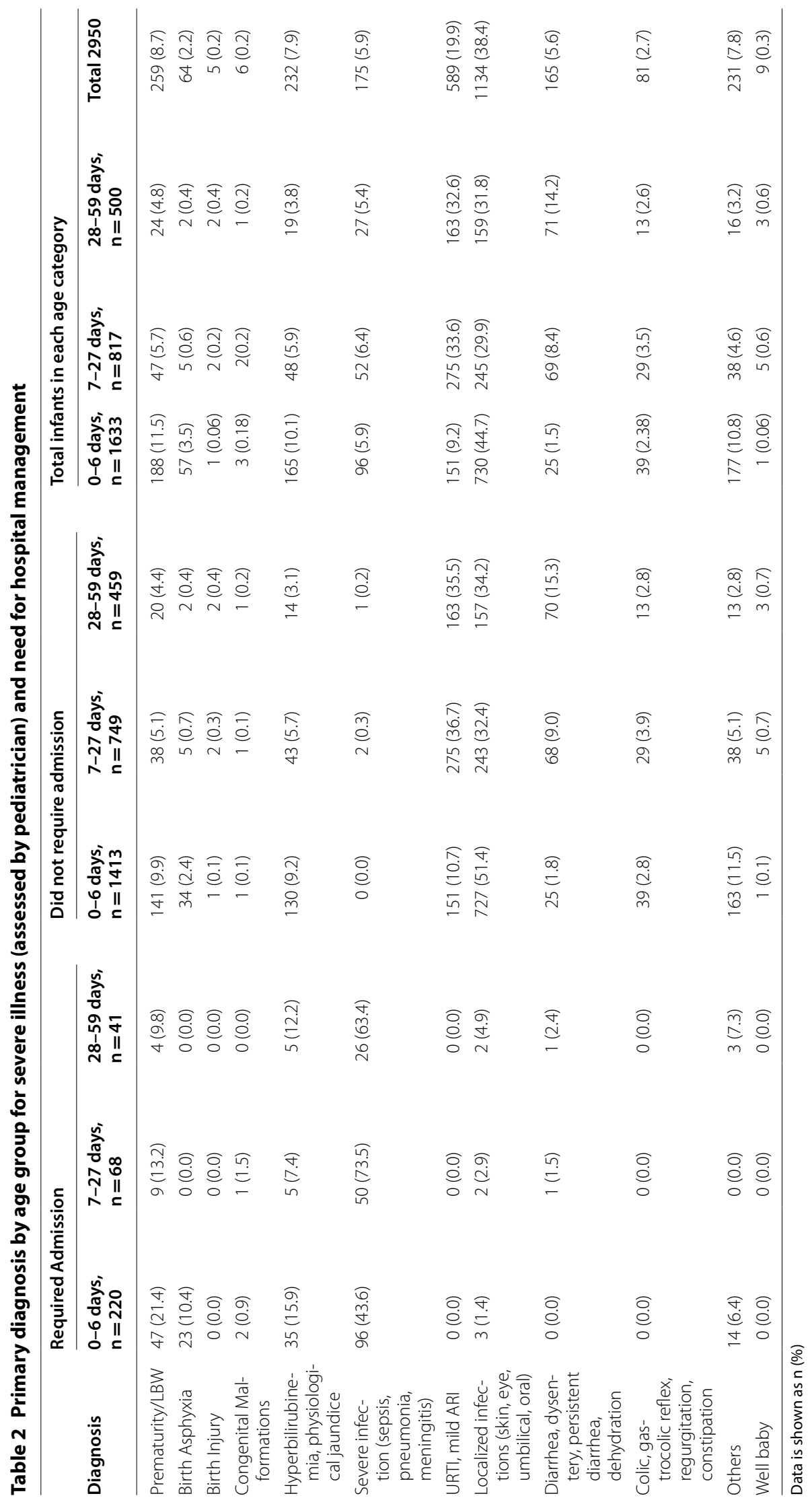


Table 3 Sensitivity and specificity of individual signs, and the 7-sign algorithm for identification of the sick infant requiring hospital admission, for each age group

\begin{tabular}{|c|c|c|c|c|c|c|}
\hline \multirow[t]{2}{*}{ Signs } & \multicolumn{2}{|l|}{$\begin{array}{l}\text { Ages } 0-6 \text { days } \\
n=1633\end{array}$} & \multicolumn{2}{|l|}{$\begin{array}{l}\text { Ages 7-27 days } \\
\mathrm{n}=817\end{array}$} & \multicolumn{2}{|l|}{$\begin{array}{l}\text { Ages 28-59 days } \\
n=500\end{array}$} \\
\hline & $\begin{array}{l}\text { Sensitivity }(95 \% \\
\mathrm{Cl})\end{array}$ & $\begin{array}{l}\text { Specificity }(95 \% \\
\text { Cl) }\end{array}$ & $\begin{array}{l}\text { Sensitivity }(95 \% \\
\mathrm{CI})\end{array}$ & $\begin{array}{l}\text { Specificity }(95 \% \\
\mathrm{Cl})\end{array}$ & $\begin{array}{l}\text { Sensitivity }(95 \% \\
\text { Cl) }\end{array}$ & Specificity $(95 \% \mathrm{Cl})$ \\
\hline $\begin{array}{l}\text { History of difficult } \\
\text { feeding }\end{array}$ & $26.0(19.7,33.0)$ & $97.2(96.2,98.0)$ & $24.1(13.9,37.2)$ & $96.6(95.0,97.8)$ & $15.0(5.7,29.8)$ & $93.7(91.1,95.7)$ \\
\hline $\begin{array}{l}\text { Movement only } \\
\text { when stimulated }\end{array}$ & $22.2(17.5,27.5)$ & $99.7(99.4,99.8)$ & $20.7(11.2,33.4)$ & $99.6(98.8,99.9)$ & $7.3(1.5,19.9)$ & $99.8(98.8,100.0)$ \\
\hline Temperature $<35.5$ & $13.0(8.5,18.7)$ & $98.0(97.1,98.7)$ & $5.2(1.1,14.4)$ & $98.9(97.9,99.5)$ & $2.4(0.1,12.9)$ & $99.3(98.1,99.9)$ \\
\hline Temperature $\geq 37.5$ & $24.7(18.6,31.7)$ & $90.8(89.2,92.3)$ & $27.6(16.7,40.9)$ & $96.3(94.6,97.5)$ & $12.2(4.1,26.2)$ & $96.0(93.8,97.6)$ \\
\hline $\begin{array}{r}\text { Respiratory } \\
\text { Rate }>60\end{array}$ & $51.4(43.9,58.8)$ & $81.6(79.5,83.5)$ & $46.6(33.3,60.1)$ & $92.1(89.9,93.9)$ & $56.1(39.7,71.5)$ & $92.2(89.3,94.4)$ \\
\hline $\begin{array}{l}\text { Severe chest } \\
\text { indrawing }\end{array}$ & $12.4(8.0,18.1)$ & $99.7(99.2,99.9)$ & $24.1(13.9,37.2)$ & $100.0(99.5,100.0)$ & $39.0(24.2,55.5)$ & $97.6(95.8,98.8)$ \\
\hline $\begin{array}{l}\text { History of convul- } \\
\text { sions }\end{array}$ & $9.7(5.9,14.9)$ & $99.5(99.0,99.8)$ & $1.7(0.0,9.2)$ & $98.7(97.6,99.4)$ & $9.8(2.7,23.1)$ & $98.5(96.9,99.4)$ \\
\hline 7-sign algorithm & $85.9(80.1,90.6)$ & $71.6(69.2,74.0)$ & $72.4(59.1,83.3)$ & $83.1(80.3,85.7)$ & $80.5(65.1,91.2)$ & $80.2(76.2,83.7)$ \\
\hline
\end{tabular}

need for hospitalization in the community setting, where such a technique proves invaluable in face of the dearth of resources and accessibility, as well as high mortality rate.

\section{Conclusion}

With relevant guidelines in place, LHVs (Lady Health Visitors) can be trained to recognize signs and symptoms of severe illnesses in infants, thereby contributing significantly towards the improvement of the infant and neonatal outcomes in a low and middle-income country like Pakistan, as well as globally.

\section{Limitations}

- Diseases in the early neonatal period are rarely reported when it comes to rural or semi-urban areas with community level health facilities, despite their immense significance in reducing the childhood mortality if detected and managed early [11-13]. To avoid this limitation, we conducted regular community surveillance to ensure maximum participation, and to avoid missing any possible cases of severe illness.

- Another limitation in our study was that the decision for referral was made by the physician purely based on history and clinical examination and was not supported by laboratory tests. Even though tests were conducted wherever indicated, the results did not affect the decision for hospital admission. In this case, there is a possibility that some cases of severe illness were missed simply because the child had not developed symptoms, or that the symptoms were not very apparent.

- We excluded infants who were previously sick and were referred by another healthcare professional in order to mimic the community population presenting to a primary healthcare facility and this led to lesser number of sick infants requiring hospital admissions.

- A separate analysis should be conducted in order to study indicators of jaundice and hyperbilirubinemia, as that too is an important cause of neonatal morbidity.

- Although it's been a long time since this study was completed and primary results were published, (primary data for this study was collected between 2003 and 2004) [3], we still think that these site specific results are of considerable value for similar low middle income settings. They would additionally be helpful for researchers updating systematic review and metanalysis in this field.

\section{Supplementary Information}

The online version contains supplementary material available at https://doi. org/10.1186/s13104-021-05486-y.

Additional file 1. Supplementary Figure and Table

\section{Abbreviations}

YICSS: Young Infants Clinical Signs and Symptoms; PHC: Primary Health Center; AKUH: Aga Khan University, Hospital; IMCl: Integrated Management of Childhood IIInesses; WHO: World Health Organization; CHW: Community Health Worker; LHV: Lady Health Visitor; NICH: National Institute of Child Health. 


\section{Acknowledgements \\ Not applicable.}

\section{Authors' contributions}

SS, KN and AM drafted the manuscript. SST coordinated the study and did the analysis. MIN and FJ supervised the analysis, write up and wrote the discussion section. NB provided valuable input throughout. AKMZ designed the study and provided valuable inputs at all stages. All authors read and approved the final manuscript.

\section{Funding}

This study was funded jointly by WHO, Boston University (through a Cooperative Agreement between Boston University and the Office of Health and Nutrition of the United States Agency for International Development; GHS-A-00-0300020-00), and Save the Children-US through a grant from the Bill \& Melinda Gates Foundation for the Saving Newborn Lives Programme. Funding bodies had no role in the design, collection, analysis, and interpretation of study data and in writing the manuscript.

\section{Availability of data and materials}

The datasets used and/or analyzed during the current study are available from the corresponding author on reasonable request.

\section{Ethical approval and consent to participate}

The study was approved by the Ethics Review Committee of Aga Khan University and by the Johns Hopkins University Institutional Review Board. Written informed consent was taken from the parent or guardian of the child.

\section{Consent for publication}

Not applicable.

\section{Competing interests}

The authors declare that they have no competing interests.

\section{Author details}

${ }^{1}$ Department of Pediatrics and Child Health, Aga Khan University, Karachi, Pakistan. ${ }^{2}$ Department of Community Health Sciences, Aga Khan University, Karachi, Pakistan. ${ }^{3}$ Salisbury District Hospital, Salisbury, UK. ${ }^{4}$ Bill \& Melinda Gates Foundation, Seattle, USA.
Received: 2 December 2020 Accepted: 13 February 2021

Published online: 24 February 2021

\section{References}

1. WHO, Global health observatory data-neonatal mortality. 2015.

2. WHO. Newborns: reducing mortality. http://www.who.int/mediacentre/ factsheets/fs333/en/. 2016

3. Young Infants Clinical Signs Study. Clinical signs that predict severe illness in children under age 2 months: a multicentre study. Lancet. 2008;371(9607):135-42.

4. Mazzi $\mathrm{E}$, et al. Clinical signs predicting severe illness in young infants (<60 days) in Bolivia. J Trop Pediatr. 2010;56(5):307-16.

5. Yeboah-Antwi K, et al. Clinico-epidemiological profile and predictors of severe illness in young infants (0-59 days) in Ghana. Ann Trop Paediatr. 2008;28(1):35-43.

6. Deorari AK, et al. Clinicoepidemiological profile and predictors of severe illness in young infants ( $<60$ days) reporting to a hospital in North India. Indian Pediatr. 2007:44(10):739-48.

7. Jeena PM, et al. Clinical profile and predictors of severe illness in young South African infants (<60 days). S Afr Med J. 2008:98(11):883-8.

8. WHO, Integrated management of childhood illnesses-Chart Booklet. 2014

9. WHO, Newborn death and illness. 2011.

10. Kumar V, Singhi S. Predictors of serious bacterial infection in infants up to 8 weeks of age. Indian Pediatr. 1994;31(2):171-80.

11. Duke T, et al. The management of sick young infants at primary health centres in a rural developing country. Arch Dis Child. 2005;90(2):200-5.

12. English $\mathrm{M}$, et al. Causes and outcome of young infant admissions to a Kenyan district hospital. Arch Dis Child. 2003:88(5):438-43.

13. Dagan $\mathrm{R}$, et al. Identification of infants unlikely to have serious bacterial infection although hospitalized for suspected sepsis. J Pediatr. 1985;107(6):855-60

\section{Publisher's Note}

Springer Nature remains neutral with regard to jurisdictional claims in published maps and institutional affiliations.
Ready to submit your research? Choose BMC and benefit from:

- fast, convenient online submission

- thorough peer review by experienced researchers in your field

- rapid publication on acceptance

- support for research data, including large and complex data types

- gold Open Access which fosters wider collaboration and increased citations

- maximum visibility for your research: over $100 \mathrm{M}$ website views per year

At BMC, research is always in progress.

Learn more biomedcentral.com/submissions 